\title{
A MEMÓRIA EM AÇÃO: BREVES CONSIDERAÇÕES SOBRE OS CONCEITOS DE MEMÓRIA E IDENTIDADE NA OBRA DE JOËL CANDAU
}

\author{
Memory in action: brief considerations about the \\ concepts of memory and identity in Joël Candau's work \\ Memoria en acción: breves consideraciones sobre los \\ conceptos de memoria e identidad en la obra de Joël Candau
}

\author{
Thales Reis Alecrim \\ Universidade Estadual Paulista, Franca, Brasil. \\ Doutorando em História na Faculdade de Ciências Humanas e Sociais da Universidade Estadual \\ Paulista (Unesp). Mestre, licenciado e bacharel em História pela Unesp. Especialista em Cultura \\ Material e Consumo: perspectiva semiopsicanalíticas pela Universidade de São Paulo (USP). E-mail: \\ thales.alecrim@gmail.com
}

RESUMO Memória e identidade, de Joël Candau, é um livro que ao mesmo tempo empreende um estado da arte dos conceitos referidos no título e propõe novas interpretações e leituras pelo viés antropológico. Dessa maneira, nesta resenha buscamos identificar as formas como essas duas categorias fundamentais para as Ciências Humanas e Sociais são construídas e fundamentadas pelo autor. Por esse motivo, optamos por expor os principais argumentos do livro e explorar os meandros de sua construção teórica e metodológica. Por fim, também propomos um breve debate sobre as relações entre memória, identidade e história, questão de fundamental importância, uma vez que demonstra como o passado pode ser mobilizado e manipulado para diversos fins, seja para fomentar identidades ou fundamentar práticas políticas.

PALAVRAS-CHAVE Memória, Identidade, História.

ABSTRACT Memory and Identity by Joël Candau is a book that both undertakes a state of the art of the concepts referred to in the title and proposes new interpretations and readings from an anthropological perspective. Thus, in this review, we seek to identify the ways in which the author constructs and supports these two fundamental categories for the Human and Social Sciences. For this reason, we chose to expose the main arguments of the book, then explore the intricacies of its theoretical and methodological construction. Finally, we also propose a brief debate on the relationships between memory, identity, and history, an issue of fundamental importance, as it demonstrates how the past can be mobilized and manipulated for different purposes, whether to foster identities or to support political practices.

KEYWORDS Memory, Identity, History.

RESUMEN La obra Memoria e identidad, de Joël Candau, emprende un estado del arte de los conceptos a los que hace referencia el título a la vez propone nuevas interpretaciones y lecturas desde una perspectiva antropológica. Así, en esta revisión buscamos identificar cómo el autor construye y sostiene estas dos categorías fundamentales para las ciencias humanas y sociales. Por esta razón, optamos por exponer los principales argumentos del libro, para luego explorar las complejidades de su construcción teórica y metodológica. 
Finalmente, también proponemos un breve debate sobre las relaciones entre memoria, identidad e historia, tema de fundamental importancia, ya que demuestra cómo el pasado puede ser movilizado y manipulado para diferentes propósitos, ya sea para fomentar identidades o apoyar prácticas políticas.

PALABRAS-CLAVE Memoria, Identidad, Historia.

O casamento entre uma escrita poética, que permite uma leitura leve, junto com uma análise rigorosa, que proporciona uma reflexão densa, constitui a obra de Joël Candau. O livro Memória e identidade (2018) busca, assim como a própria introdução alega, explicitar a transição da memória e da identidade das funções individuais para os planos coletivos. $O$ autor, comprometido com a antropologia cultural, relaciona esses conceitos buscando demonstrar como tais mecanismos, presentes no indivíduo, podem ou não se manter e estruturar a coesão de determinados grupos sociais.

Dessa maneira, na primeira metade do livro, Candau analisa a função da memória no indivíduo, enquanto na segunda debate incisivamente as formas de transmissão social. Assim, uma pergunta atravessa todo o livro: qual compartilhamento é possível entre o indivíduo e o grupo? Debruçando-se sobre essa extensa questão, o autor dialoga com uma ampla bibliografia, procurando em diferentes autores discussões que tangenciem esse debate e privilegiando as formas de compreensão que abordam a importância da memória para a construção identitária, seja do grupo, seja do sujeito.

Num primeiro momento, o antropólogo apresenta esses conceitos junto à ideia de cultura, uma vez que são, por instância, interligados e interdependentes, como pontos fundamentais para as Ciências Humanas. Assim, a memória é definida como as narrativas que sobreviveram ao passado e são constantemente relembradas, denotando, portanto, um sentido de coesão para o indivíduo e para o grupo. Nesse passo, a identidade é, na verdade, "a memória em ação", pois é por meio dela que se criam as narrativas de pertencimento identitário. Por fim, a cultura é aqui entendida como o repertório simbólico que possibilita a coesão social, atravessando tanto as definições de identidade como as de memória. Para Candau, esses três conceitos são operados no nível sociológico e antropológico com o intuito de compreender as formas de organização social e de concepção do sujeito dentro desse referencial.

Diante disso, o autor deixa claro, desde o primeiro momento, que nenhuma memória é exatamente fiel ao passado, pois ela é moldada e reconfigurada para ser encaixada na narrativa identitária de determinado momento. Há uma dinâmica curiosa que transita entre a fidelidade e a traição, pois o passado é mantido, mas sempre ressignificado ou manipulado. Nesse sentido, o movimento memorial é duplo, pois suas forças advêm do passado, mas são rebatidas pelas demandas do presente. Nesse jogo entre passado e presente, são negociados os termos das narrativas que sustentam a coesão, seja do sujeito, seja do grupo, e, por fim, essas forças são combinadas para projetar um possível futuro para aquele indivíduo ou comunidade.

Candau sugere que os níveis de compartilhamento são sempre relativos, isto é, quanto menor o grupo, mais chances existem de os membros compartilharem memórias e um senso comum de identidade. Por outro lado, quanto maior o grupo, mais fragmentada e impossível se torna a possibilidade de compartilhamento. Neste sentido, é mais fácil existirem memórias e identidades coletivas em pequenas vilas ou núcleos familiares do que em metrópoles, nações e continentes. 
Além disso, existem graus de pertinência e manutenção dessas memórias e, por isso, devem existir suportes de registro, sejam mecanismos orais ou escritos. Portanto, não se trata de afirmar se a memória que fundamenta tal ou qual identidade é verdadeira, mas sim de saber em que nível a memória foi preservada, mantendo-se contundente para a comunidade. Os suportes podem variar desde agentes ou indivíduos que "guardam" e transmitem as memórias até condições mais contemporâneas, como a escrita e os arquivos.

Entretanto, a partir disso, Candau tece uma contundente crítica ao modo como as sociedades contemporâneas lidam com o seu repertório memorial. $\mathrm{O}$ interdito do esquecimento atravessa a atividade memorialística, ou seja, para que uma memória permaneça, outra deve sucumbir. Dessa maneira, há um processo de seleção, uma escolha e uma manipulação desse repertório, em que se decide o que pode ser incluído dentro da narrativa identitária e o que deve ser excluído. Porém, devido aos modernos meios de conservação arquivística, a sociedade contemporânea não passa pelos processos de esquecimento e seleção, pois tudo é mantido e conservado, ocasionando, assim, o que o autor denomina de iconorréia - uma produção excessiva de imagens que, em vez de contribuírem para a construção de um senso comum de pertencimento, acabam gerando o oposto, pois, devido ao excesso de memórias, criam narrativas identitárias difusas.

Por esse motivo, o autor faz uma diferenciação importante. Por um lado, existem as memórias vivas, aquelas que, por serem transmitidas e por circularem contundentemente pelo grupo, têm uso social e possibilitam a reinvenção e a ressignificação. Por outro, existem as memórias mortas, que são arquivadas, petrificadas e que não exercem nenhuma função social devido ao esgotamento da sua capacidade de reinvenção. Dessa maneira, a iconorréia denominada por Candau se refere a esse último tipo de memória, que, por estar fora de circulação, não exerce nenhuma função dentro do repertório de signos que fornece coesão ao grupo. Em vez disso, opera na contramão desse processo ao dissolver os laços que unem esses indivíduos, uma vez que o interdito do esquecimento é negado, fazendo, assim, que as narrativas mais contundentes não sejam selecionadas para a manutenção do sentimento de pertencimento daquele grupo.

Essa "compulsão arquivística” que gera essa profusão de memórias mortas é uma reação dos contemporâneos à percepção da aceleração no presente, ou seja, uma maneira de apreender o tempo para impedir a dissolução da existência. Claro que, além desse sentimento de efemeridade, ainda existe a emergência de novas tecnologias capazes de armazenar cada vez mais informações. Dessa maneira, unem-se as possibilidades técnicas com uma percepção existencial.

Nesse momento surge uma questão: onde está a tradição e qual papel ela opera dentro da dinâmica entre memória, identidade e cultura? Para um determinado grupo, a tradição é interpretada como a autoridade que emana do passado - mesmo que o passado seja reinterpretado e manipulado de acordo com as demandas do presente, ele ainda é percebido como uma fonte de poder e legitimidade. Através dessa autoridade, a tradição realiza um papel de organização daquele grupo, legitimando hierarquias e afirmando a identidade, o que a leva, por conseguinte, devido ao teor dessas funções, a ser respeitada, mas também acomodada e recriada.

A partir disso, voltamos para a principal pergunta proposta pelo livro: como se dá o compartilhamento entre o indivíduo e o grupo? A resposta está dada: através da transmissão, seja ela oral ou por meio de um suporte. 
Contudo, isso implica um problema: o quanto desse compartilhamento é possível? Para essa delicada questão, Candau propõe que consideremos a variação do esquecimento como forma de estreitar ou afrouxar os laços. Dessa maneira, o esquecimento é mais determinante para a manutenção da coesão de um grupo do que as lembranças propriamente ditas, pois, através dele, são operadas as seleções que porventura constituirão o repertório do grupo.

Por esse motivo, a memória é delimitada por quadros sociais que determinam o seu poder de influência, e, ao mesmo tempo, esses quadros ordenam as dinâmicas entre a lembrança e o esquecimento. Dessa forma, cria-se a filiação do indivíduo ao grupo, pois esse laço passa pela afetividade, cuja manutenção é realizada através da repetição e de uma considerável possibilidade de reinvenção dessa memória. Logo, o jogo memorial é determinado mais pelo presente e pelo seu manuseamento do que pelo passado.

Seguindo essa reflexão, o autor demonstra como a História é filha da memória. Pierre Nora (1993) determina que a diferença entre essas duas formas de conhecimento sobre o passado está justamente na maneira como elas concebem aquilo que foi e já não é mais. Assim, a História tem um olhar secular e racionalizante, enquanto a memória opera uma mirada mística e afetuosa (NORA, 1993). Candau utiliza essa concepção e afirma que ambas compartilham aspectos comuns de construção do saber, pois são atravessadas pelos interesses do presente e se valem da seleção e do estilhaço para a construção de seus materiais. Contudo, a memória é, por assim dizer, mais poderosa do que a História, pois atravessa esta última, comprometendo sua suposta imparcialidade.

Dessa maneira, retornamos para Michel de Certeau (1982), pois, mesmo se passando muitas décadas, o seu manifesto sobre a operação historiográfica continua atual. A História, com toda certeza, é atravessada pela memória; contudo, o que distingue uma da outra é justamente o critério de seleção sobre o que será narrado do passado. Assim, o que move a disciplina é o interesse em acessar a verossimilhança com o passado, pois a possibilidade de acessar o passado tal qual ele foi já nos é vedada, porque nosso acesso aos eventos anteriores se dá por intermédio das fontes. O compromisso científico da História se mantém, pois a busca dessa semelhança com o passado é operada por um método que é transformado em escrita para o acesso da comunidade. No entanto, em consonância com Candau (2018) e Nora (1993), Certeau (1982) afirma que a construção desse conhecimento é marcada pelo interesse do tempo presente e que, por esse motivo, devemos sempre considerar o local da escrita como um ponto determinante para a interpretação da história.

Nesse sentido, através do belíssimo livro de Joël Candau, acessamos uma extensa reflexão contemporânea sobre as formas de se interpretar o passado, visto que este não está petrificado ou congelado e ganha vida a cada nova indagação ou reflexão sobre seus eventos. Esses estudos demonstram o quanto os grupos humanos se apoiam na necessidade de recontar o passado para dar sentido ao presente. Portanto, a partir do presente, opera-se continuamente um movimento de ida à ancestralidade com o intuito de manipular memórias que possam suportar narrativas identitárias contemporâneas que, por sua vez, sempre serão provisórias. Nunca existirá uma identidade sólida e monolítica, pois, por sua própria essência, ela é plural e dependente dos jogos memoriais entre as demandas do presente e aquilo que se sabe sobre o passado. 


\section{REFERÊNCIAS}

CANDAU, Joël. Memória e identidade. Tradução de Maria Leticia Ferreira. São Paulo: Contexto, 2018.

CERTEAU, Michel. A escrita da história. Rio de Janeiro: Forense Universitária, 1982.

NORA, Pierre. Entre memória e história: a problemática dos lugares. Projeto História, São Paulo, v. 10, p. 7-28, 1993. 